\title{
Effect of Radiation Therapy Techniques on Outcome in N3-positive IIIB Non-small Cell Lung Cancer Treated with Concurrent Chemoradiotherapy
}

\author{
Jae Myoung Noh, MD \\ Jin Man Kim, BA \\ Yong Chan Ahn, MD, PhD \\ Hongryull Pyo, MD, PhD \\ BoKyong Kim, MD, PhD \\ Dongryul Oh, MD \\ Sang Gyu Ju, PhD \\ Jin Sung Kim, PhD \\ Jung Suk Shin, MS \\ Chae-Seon Hong, PhD \\ Hyojung Park, MD \\ Eonju Lee, MD
}

Department of Radiation Oncology,

Samsung Medical Center,

Sungkyunkwan University

School of Medicine, Seoul, Korea

Correspondence: Yong Chan Ahn, MD, PhD

Department of Radiation Oncology,

Samsung Medical Center,

Sungkyunkwan University School of Medicine,

81 Irwon-ro, Gangnam-gu, Seoul 06351, Korea

Tel: 82-2-3410-2602

Fax: 82-2-3410-2619

E-mail: ahnyc@skku.edu

Received May 28, 2014

Accepted August 1, 2014

Published Online February 12, 2015

\section{Purpose}

This study was conducted to evaluate clinical outcomes following definitive concurrent chemoradiotherapy (CCRT) for patients with N3-positive stage IIIB (N3-IIIB) non-small cell lung cancer (NSCLC), with a focus on radiation therapy (RT) techniques.

\section{Materials and Methods}

From May 2010 to November 2012, 77 patients with N3-IIIB NSCLC received definitive CCRT (median, 66 Gy). RT techniques were selected individually based on estimated lung toxicity, with 3-dimensional conformal RT (3D-CRT) and intensity-modulated RT (IMRT) delivered to $48(62.3 \%)$ and $29(37.7 \%)$ patients, respectively. Weekly docetaxel/paclitaxel plus cisplatin $(67,87.0 \%)$ was the most common concurrent chemotherapy regimen.

\section{Results}

The median age and clinical target volume (CTV) were 60 years and $288.0 \mathrm{~cm}^{3}$, respectively. Patients receiving IMRT had greater disease extent in terms of supraclavicular lymph node (SCN) involvement and CTV $\geq 300 \mathrm{~cm}^{3}$. The median follow-up time was 21.7 months. Fortyfive patients (58.4\%) experienced disease progression, most frequently distant metastasis (39, 50.6\%). In-field locoregional control, progression-free survival (PFS), and overall survival (OS) rates at 2 years were $87.9 \%, 38.7 \%$, and $75.2 \%$, respectively. Although locoregional control was similar between RT techniques, patients receiving IMRT had worse PFS and OS, and SCN metastases from the lower lobe primary tumor and CTV $\geq 300 \mathrm{~cm}^{3}$ were associated with worse OS. The incidence and severity of toxicities did not differ significantly between RT techniques.

\section{Conclusion}

IMRT could lead to similar locoregional control and toxicity, while encompassing a greater disease extent than 3D-CRT. The decision to apply IMRT should be made carefully after considering oncologic outcomes associated with greater disease extent and cost.

\section{Key words}

Non-small cell lung carcinoma, Concurrent chemoradiotherapy, Stage IIIB-N3, Intensity-modulated radiotherapy

\section{Introduction}

Definitive concurrent chemoradiotherapy (CCRT) has become the standard treatment for patients with N3-positive stage IIIB (N3-IIIB) non-small cell lung cancer (NSCLC) [1-4]. Delivery of high radiation dose, which is usually recommended for improved locoregional control and survival [5], is often limited by the risk of lung toxicity, which presents as radiation pneumonitis and subsequent pulmonary fibrosis [6,7]. The extent of metastatic regional lymph nodes (LN) in patients with N3-IIIB NSCLC is quite heterogeneous [8], and it often becomes difficult to safely cover the whole disease extent within the high radiation dose volume when using conventional 3-dimensional conformal radiation therapy (3D-CRT) technique. Metastasis to the supraclavicular lymph node (SCN) from the lower lobe primary tumor is a typical problematic example. Introduction of the intensity-modulated radiation therapy (IMRT) technique has greatly improved the target coverage at high 
radiation dose while sparing normal lung tissue [9-11]. Previous studies that employed IMRT were more or less successful at achieving favorable clinical outcomes in terms of locoregional control and survival and reducing the incidences of pulmonary and esophageal toxicities, among which the proportion of patients with $\mathrm{N} 3$ or IIIB disease accounted for $32 \%-60 \%$ [12-14]. Based on these studies, the use of IMRT for treatment of patients with stage III NSCLC has become increasingly popular [15].

The use of IMRT is still limited in Korea, mainly because the national health insurance plan covers only the 3D-CRT technique and does not reimburse the cost of IMRT during treatment of patients with NSCLC. Given this limitation, few clinical studies on the use of IMRT for lung cancer patients have been conducted in Korea [16]. Since May of 2010, the authors at Samsung Medical Center (SMC) have been using IMRT to treat patients with extensive NSCLC. Based on their known disease extent, these patients were believed to be at excessive risk of pulmonary toxicity if treated with conventional 3D-CRT. This study was conducted to comparatively evaluate treatment outcomes based on the radiation therapy (RT) techniques chosen (IMRT vs. 3D-CRT) for evaluation of N3-IIIB NSCLC patients receiving definitive CCRT.

\section{Materials and Methods}

From May 2010 to November 2012, 81 patients with newly diagnosed, pathologically confirmed N3-IIIB NSCLC were treated with definitive CCRT at SMC. Since trimodality therapy strategy, which includes surgical resection following neoadjuvant CCRT, has been the primary treatment option for N2-IIIA patients at SMC [17], patients with N3-IIIB disease constituted the majority of those receiving definitive CCRT. Among these, two patients received curative surgical resection following definitive CCRT, and another two received a combination of 3D-CRT and IMRT. After excluding these four patients, we retrospectively reviewed the medical records of 77 patients who were the basis of the current study. The RT techniques were selected individually based on the known disease extent, performance and cardiopulmonary functional status of the patients, and the subsequent estimated risk of pulmonary toxicity. When the estimated $\mathrm{V}_{20}$ exceeded $40 \%$, the mean lung dose exceeded 25 Gy, and / or the maximum spinal cord dose exceeded 50 Gy if treated with conventional 3D-CRT, they were offered the IMRT option. It was explained to all the IMRT candidate patients that IMRT was not covered by the Korean insurance policy, and they were offered alternative option of induction chemotherapy followed by sequential RT in case the IMRT cost was not affordable. All IMRT candidate patients agreed to pay the extra-cost, and the current study was approved by the Institutional Review Board of Samsung Medical Center (2013-08-027).

The initial diagnosis of NSCLC was pathologically confirmed in all patients based on either bronchoscopy or percutaneous fine-needle aspiration and biopsy. The diagnostic and staging work-ups included complete history and physical examination, simple chest radiographs, chest computed tomography (CT) scan, routine blood tests, and ${ }^{18}$ fluoro-deoxyglucose positron emission tomography (PET) or PET/CT scan. For accurate nodal staging, fine-needle aspiration from the SCN was performed in 33 patients $(42.9 \%)$, endobronchial ultrasound-guided transbronchial needle aspiration in $29(37.7 \%)$, and mediastinoscopic biopsy in nine $(9.1 \%)$. N3 stage assignment was made primarily based on clinical judgment without histologic confirmation in 15 patients (19.5\%) who showed abnormal findings on PET/CT scan and were at very high risk to undergo any invasive procedures.

For treatment planning, contrast enhancing simulation CT scans of all patients were conducted. Simulation CT scans were typically performed in the supine position at a thickness of 2.5-5 mm. The gross tumor volume (GTV) was defined as the volume of the tumor identified based on all available clinical information, including radiologic imaging, PET scan, bronchoscopy, and mediastinoscopy. The clinical target volume (CTV) was delineated by a 5-mm margin extending in all directions from the GTV, and the margins were modified in accordance with the adjacent organs if necessary. The internal target volume was delineated by combining all GTVs and CTVs delineated on each respiratory phase based on 4-dimensional computed tomography (4D-CT), which was acquired in 29 patients (37.7\%). Elective irradiation of the clinically uninvolved lymph node was not allowed principally. A 5-8 mm margin extension around the CTV was included to generate the planning target volume. The Pinnacle ${ }^{3}$ system (ver. 8.0, Philips Medical Systems, Madison, WI) was used to calculate the radiation dose.

During the study period, 48 patients $(62.3 \%)$ were treated with 3D-CRT (group I) and 29 (37.7\%) with IMRT (group II). The median RT dose prescribed to the CTV was $66 \mathrm{~Gy}$ in 33 fractions over 6.5 weeks. The 3D-CRT plan was typically composed of three or four beams of 4-, 6-, or 10-MV photons from a linear accelerator (Varian Medical System, Palo Alto, CA). The IMRT plan was mainly composed of six median coplanar beams of 6-MV photons using the step-and-shoot method. Whenever feasible and indicated, the second CT simulation and adaptive re-plan was generated to accommodate tumor regression and reduce the normal tissue toxicity, typically at fractions of 20-23. The normal tissue constraints used were as follows: maximum spinal cord dose $<46 \mathrm{~Gy}$; 
Table 1. Clinical characteristics according to radiotherapy technique

\begin{tabular}{|c|c|c|c|}
\hline Characteristic & $3 \mathrm{D}-\mathrm{CRT}(\mathrm{n}=48)$ & IMRT (n=29) & p-value \\
\hline Age (yr) & $62(44-72)$ & $59(40-80)$ & 0.744 \\
\hline \multicolumn{4}{|l|}{ Sex } \\
\hline Male & $35(72.9)$ & $18(62.1)$ & \multirow{2}{*}{0.390} \\
\hline Female & $13(27.1)$ & $11(37.9)$ & \\
\hline Smoking history & $34(70.8)$ & $17(58.6)$ & 0.272 \\
\hline $\mathrm{FEV}_{1}(\mathrm{~L})$ & $2.49(1.17-3.90)$ & $2.50(1.46-3.71)$ & 0.791 \\
\hline \multicolumn{4}{|l|}{ ECOG performance } \\
\hline 0 & $10(20.8)$ & $6(20.7)$ & \multirow{2}{*}{0.988} \\
\hline 1 & $38(79.2)$ & $23(79.3)$ & \\
\hline \multicolumn{4}{|l|}{ Primary site } \\
\hline Upper-middle lobes & $39(81.3)$ & $13(44.8)$ & \multirow[t]{2}{*}{0.001} \\
\hline Lower lobes & $9(18.7)$ & $16(55.2)$ & \\
\hline \multicolumn{4}{|l|}{ Histology } \\
\hline Adenocarcinoma & $31(64.6)$ & $22(75.9)$ & \multirow[t]{3}{*}{0.053} \\
\hline Squamous cell carcinoma & $15(31.2)$ & $3(10.3)$ & \\
\hline Others & $2(4.2)$ & $4(13.8)$ & \\
\hline Tumor size $(\mathrm{cm})$ & $3.8(1.3-12.2)$ & $3.7(1.0-9.2)$ & 0.785 \\
\hline \multicolumn{4}{|l|}{ Clinical T classification } \\
\hline cT1-2 & $34(70.8)$ & $23(79.3)$ & \multirow[t]{2}{*}{0.411} \\
\hline cT3-4 & $14(29.2)$ & $6(20.7)$ & \\
\hline \multicolumn{4}{|l|}{$\mathrm{N} 3$ involvement region } \\
\hline Contralateral mediastinum & $29(60.4)$ & $7(24.1)$ & 0.002 \\
\hline Supraclavicular & $26(54.2)$ & $24(82.8)$ & 0.011 \\
\hline
\end{tabular}

Values are presented as median (range) or number (\%). 3D-CRT, three-dimensional conformal radiotherapy; IMRT, intensity-modulated radiotherapy; $\mathrm{FEV}_{1}$, forced expiratory volume in 1 second; ECOG, Eastern Cooperative Oncology Group.

relative lung volumes receiving $20 \mathrm{~Gy} / 5 \mathrm{~Gy}<35 \% /<65 \%$; and the mean lung dose $<20 \mathrm{~Gy}$. The most common concurrent chemotherapeutic regimen was weekly paclitaxel or docetaxel plus cisplatin or carboplatin, which was administered to 67 patients $(87.0 \%)$. Ten of these patients received additional consolidation chemotherapy following CCRT. The remaining ten patients $(13.0 \%)$ received pemetrexed or etoposide plus cisplatin, while nine of these patients received consolidation chemotherapy.

The first follow-up and response evaluation was scheduled at 1 month after completion of CCRT and included a chest $\mathrm{CT}$ scan. Subsequent follow-up evaluations were conducted at 3-4 month intervals thereafter, and included alternating chest CT and whole-body PET/CT scans. The early toxicities of treatment-related pneumonitis (TRP) and esophagitis were graded using the Common Terminology Criteria for Adverse Events (CTCAE), ver. 4.0. The primary endpoints were the progression-free survival (PFS) and the overall survival (OS), while the secondary endpoints were the in-field locoregional control (LRC) and patterns of disease progression. All intervals were calculated from the dates of the CCRT start until the events or the latest follow-up. In-field locoregional progression was defined as disease progression within the irradiated volume inside the thorax, and included the ipsilateral hilum, ipsilateral and /or contralateral mediastinum, and ipsilateral and/or contralateral $\mathrm{SCN}$, but not hematogenous lung-to-lung metastasis.

A chi-square test was used to compare the patients' clinical characteristics and the dose-volume parameters based on the $\mathrm{RT}$ techniques used. A t test was used to compare continuous variables such as age, forced expiratory volume in 1 second, and tumor size. The rates of PFS, OS, and LRC were calculated and compared using the Kaplan-Meier method and the log-rank test, respectively. Factors having a p-value of $<0.2$ upon univariate analysis were entered into Cox proportional hazards regression analysis. A p-value of $\leq 0.05$ was considered statistically significant, and the SAS software (ver. 9.1.3, SAS Institute Inc., Cary, NC) was used for statistical analyses. 
Table 2. Dose-volume parameters according to radiotherapy techniques

\begin{tabular}{|c|c|c|c|}
\hline Variable & 3D-CRT (n=48) & IMRT (n=29) & p-value \\
\hline $\operatorname{CTV}\left(\mathrm{cm}^{3}\right)$ & $279.3(89.4-1,543.3)$ & 357.5 (89.3-762.7) & 0.706 \\
\hline \multicolumn{4}{|l|}{ CTV } \\
\hline$<300 \mathrm{~cm}^{3}$ & $28(59.3)$ & $10(34.5)$ & 0.043 \\
\hline$\geq 300 \mathrm{~cm}^{3}$ & $20(41.7)$ & $19(65.5)$ & \\
\hline \multicolumn{4}{|l|}{ Total lung } \\
\hline Mean dose (Gy) & $18.4(9.3-28.0)$ & $19.6(14.6-25.2)$ & 0.031 \\
\hline $\mathrm{V}_{5}(\%)$ & $57.2(29.8-72.9)$ & $65.1(48.4-90.0)$ & $<0.001$ \\
\hline $\mathrm{V}_{10}(\%)$ & $48.6(24.5-63.5)$ & $51.8(41.8-62.9)$ & 0.107 \\
\hline $\mathrm{V}_{15}(\%)$ & $40.6(18.1-54.5)$ & $42.3(34.7-53.6)$ & 0.052 \\
\hline $\mathrm{V}_{20}(\%)$ & $32.8(14.3-50.0)$ & $35.6(28.2-45.9)$ & 0.061 \\
\hline \multicolumn{4}{|l|}{ Esophagus } \\
\hline Maximum dose (Gy) & $67.1(55.3-74.7)$ & $68.4(60.0-77.3)$ & 0.007 \\
\hline Mean dose (Gy) & $33.2(12.5-55.8)$ & $35.1(16.1-52.0)$ & 0.111 \\
\hline $\mathrm{V}_{30}(\%)$ & $52.1(15.2-87.7)$ & $55.9(15.8-79.6)$ & 0.520 \\
\hline $\mathrm{V}_{45}(\%)$ & $44.2(3.7-74.9)$ & $48.8(1.2-76.5)$ & 0.526 \\
\hline \multicolumn{4}{|l|}{ Spinal cord } \\
\hline Maximum dose (Gy) & $43.9(10.5-57.4)$ & $43.1(32.3-48.4)$ & 0.708 \\
\hline \multicolumn{4}{|l|}{ Heart } \\
\hline Median dose (Gy) & $8.6(0.5-42.4)$ & $16.4(1.5-35.0)$ & 0.001 \\
\hline
\end{tabular}

Values are presented as median (range) or number (\%). 3D-CRT, three-dimensional conformal radiotherapy; IMRT, intensity-modulated radiotherapy; $C T V$, clinical target volume; $V_{D}$, percentage volume of organ receiving $\geq D$ Gy.

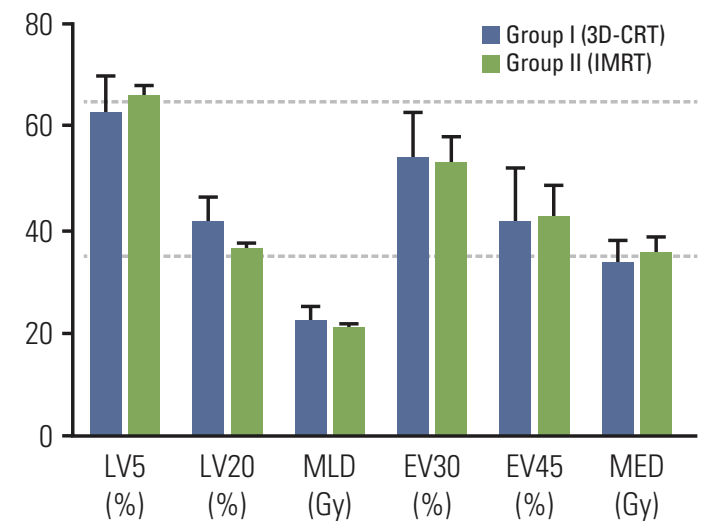

Fig. 1. Dose-volume parameters for lung and esophagus in patients with supraclavicular lymph node (SCN) originating from a lower lobe primary tumor. 3D-CRT, 3-dimensional conformal radiation therapy; IMRT, intensity-modulated radiation therapy; LV5 and LV20, volumes of the normal lung received $\geq 5$ Gy and $\geq 20 \mathrm{~Gy}$; MLD, mean lung dose; EV30 and EV45, volumes of the normal esophagus received $\geq 30$ Gy and $\geq 45$ Gy; MED, mean esophagus dose. Data are presented as the mean \pm standard error.

\section{Results}

The clinical characteristics based on the RT techniques are summarized in Table 1. The median age of all patients was 60 years (range, 40 to 80 years). Age, sex, smoking history, performance status, and clinical $\mathrm{T}$ classification did not differ between groups. Adenocarcinoma was the most common histology (53 patients, 68.8\%), followed by squamous cell carcinoma (18 patients, $23.4 \%$ ). The median tumor size measured on the initial CT was $3.8 \mathrm{~cm}$ (range, 1.0 to $12.2 \mathrm{~cm}$ ). Group II (IMRT) patients had significantly more frequent primary tumors located in the lower lobes $(p=0.001)$ and $\mathrm{SCN}$ involvement $(\mathrm{p}=0.011)$ than group I (3D-CRT). Among 50 patients with SCN involvement, 16 had primary tumors located in the lower lobes, which was also more frequent in group II than in group I (13/24 patients, $54.2 \%$ vs. $3 / 26$ patients, $11.5 \%$ ). The median CTV of all patients was 288.0 $\mathrm{cm}^{3}$ (range, 89.3 to $1,543.3 \mathrm{~cm}^{3}$ ). Although the median CTV tended to be larger in group II than group I (3D-CRT), this difference was not statistically significant according to a t test ( $p=0.706)$ (Table 2). When the CTVs were stratified into groups $\left(<300 \mathrm{~cm}^{3}\right.$ vs. $\left.\geq 300 \mathrm{~cm}^{3}\right)$, group II was associated with larger CTV more frequently than group I ( $p=0.043$ ). Since patients receiving IMRT generally had a greater extent 
Table 3. Outcomes according to treatment groups

\begin{tabular}{lccc} 
Variable & 3D-CRT (n=48) & IMRT ( $\mathbf{n = 2 9 )}$ & Overall (n=77) \\
Disease progression & $24(50.0)$ & $21(72.4)$ & $45(58.4)$ \\
Time to progression (mo) & $9.1(3.9-35.0)$ & $6.0(2.5-15.9)$ & $8.2(2.5-35.0)$ \\
Patterns of failures & & & \\
$\quad$ Locoregional & $4(8.3)$ & $2(6.9)$ & $6(7.8)$ \\
Distant & $17(35.4)$ & $15(51.7)$ & $32(41.6)$ \\
$\quad$ Both & $3(6.3)$ & $4(13.8)$ & $7(9.1)$ \\
Esophagitis & & & \\
$\quad$ Grade $\leq 2$ & $41(85.4)$ & $21(72.4)$ & $62(80.5)$ \\
Grade 3 & $7(14.6)$ & $8(27.6)$ & $15(19.5)$ \\
Pneumonitis & & & \\
Grade 1 & $32(66.7)$ & $22(75.9)$ & $54(70.1)$ \\
Grade $\geq 2$ & $16(33.3)$ & $7(24.1)$ & $23(29.9)$ \\
\hline
\end{tabular}

Values are presented as number (\%) or median (range). 3D-CRT, three-dimensional conformal radiotherapy; IMRT, intensity-modulated radiotherapy.

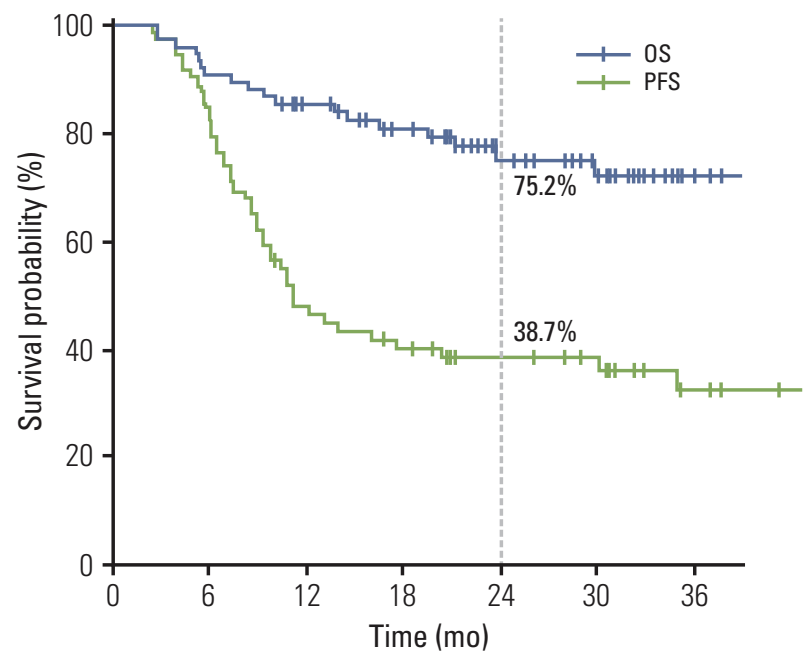

Fig. 2. Progression-free survival (PFS) and overall survival (OS) after definitive concurrent chemoradiotherapy in patients with N3-positive stage IIIB non-small cell lung cancer.

of disease, the mean lung and heart doses were higher in group II than in group I. However, the normal tissue doses generally met the constraints described above. Among the 16 patients with SCN metastasis from the lower lobe primary tumors, dose-volume parameters for the lungs and esophagus were generally similar (Fig. 1).

The median follow-up duration was 21.7 months (range, 2.3 to 43.1 months). During the follow-up period, 45 patients $(58.4 \%)$ experienced disease progression (Table 3 ). The most common first failure pattern was distant metastasis observed in 39 patients (50.6\%), followed by locoregional progression in 13 patients (16.9\%). Among 13 patients with locoregional failure, nine showed progression within the RT volume, six from group I and three from group II. There were seven patients $(9.1 \%)$ who presented with both locoregional and distant progression. The organs involved via distant metastasis were the lung in 12 patients, the brain in nine, bone in eight, and the liver in five. The median duration of PFS was 11.1 months, and the 1- and 2-year rates of PFS were $47.9 \%$ and $38.7 \%$, respectively (Fig. 2). The 1- and 2-year rates of in-field LRC were $87.9 \%$ and $85.0 \%$, respectively. A total of 18 patients $(23.4 \%)$ died during the follow-up period. Pulmonary causes, such as pneumonia, pneumonitis, and acute respiratory distress syndrome, were responsible for the deaths of two patients, one from group I and the other from group II, while TRP was not the direct cause of death for two patients. In addition, one patient died of myocardial infarction. The 1- and 2-year rates of OS were $85.5 \%$ and $75.2 \%$, respectively (Fig. 2). The incidence of CTACE grade 3 esophagitis was $19.5 \%$, which was not different between groups I and II (14.6\% vs. $27.6 \%, \mathrm{p}=0.163)$. Although patients receiving IMRT had significantly larger disease extent and received higher lung dose, the incidence of grade $\geq 2$ pneumonitis was not higher in group II than group I ( $33.3 \%$ vs. $24.1 \%, p=0.393$ ). Among the 16 patients with SCN metastasis from the lower lobe primary tumor, grade $\geq 2$ pneumonitis developed in three patients, one from group I and two from group II. Grade 3 esophagitis occurred in four patients in group II.

The clinical outcomes based on the probable prognostic factors are summarized in Tables 4 and 5. According to univariate analyses, IMRT technique $(\mathrm{p}=0.001)$, age $<60$ 
Table 4. Prognostic factors affecting survival outcomes upon univariate analysis in patients with N3-positive stage IIIB non-small cell lung cancer

\begin{tabular}{|c|c|c|c|c|c|c|c|}
\hline \multirow{2}{*}{ Variable } & \multirow{2}{*}{ No. } & \multicolumn{2}{|c|}{ PFS } & \multicolumn{2}{|c|}{ OS } & \multicolumn{2}{|c|}{ In-field LRC } \\
\hline & & 2-Year rate $(\%)$ & p-value & 2-Year rate $(\%)$ & p-value & 2-Year rate $(\%)$ & p-value \\
\hline \multicolumn{8}{|l|}{ Treatment group } \\
\hline 3D-CRT & 48 & 50.10 & 0.001 & 83.50 & 0.007 & 89.40 & 0.432 \\
\hline IMRT & 29 & 19.30 & & 61.70 & & 72.40 & \\
\hline \multicolumn{8}{|l|}{ Sex } \\
\hline Male & 53 & 42.50 & 0.229 & 71.00 & 0.311 & 83.40 & 0.740 \\
\hline Female & 24 & 30.10 & & 85.20 & & 87.50 & \\
\hline \multicolumn{8}{|l|}{ Age (yr) } \\
\hline$<60$ & 35 & 22.90 & 0.019 & 77.00 & 0.753 & 92.30 & 0.635 \\
\hline$\geq 60$ & 42 & 54.00 & & 74.50 & & 80.60 & \\
\hline \multicolumn{8}{|l|}{ Histology } \\
\hline Adenocarcinoma & 53 & 28.70 & 0.002 & 75.60 & 0.160 & 83.70 & 0.636 \\
\hline Squamous cell carcinoma & 18 & 75.00 & & 83.30 & & 86.70 & \\
\hline Others & 6 & 16.70 & & 44.40 & & 83.30 & \\
\hline \multicolumn{8}{|l|}{ Clinical T classification } \\
\hline cT1-2 & 48 & 38.70 & 0.904 & 76.80 & 0.722 & 85.10 & 0.948 \\
\hline cT3-4 & 29 & 39.00 & & 70.00 & & 85.20 & \\
\hline \multicolumn{8}{|l|}{ SCN involvement } \\
\hline Yes & 50 & 34.20 & 0.320 & 75.30 & 0.894 & 83.50 & 0.686 \\
\hline No & 27 & 46.30 & & 74.50 & & 86.60 & \\
\hline \multicolumn{8}{|l|}{ SCN from lower lobe } \\
\hline Yes & 16 & 23.50 & 0.160 & 60.60 & 0.019 & 80.00 & 0.856 \\
\hline No & 61 & 42.20 & & 79.10 & & 85.70 & \\
\hline \multicolumn{8}{|l|}{ Clinical target volume $\left(\mathrm{cm}^{3}\right)$} \\
\hline$<300$ & 38 & 46.00 & 0.139 & 91.20 & 0.001 & 88.40 & 0.834 \\
\hline$\geq 300$ & 39 & 31.00 & & 59.10 & & 80.10 & \\
\hline
\end{tabular}

PFS, progression-free survival; OS, overall survival; LRC, locoregional control; 3D-CRT, three-dimensional conformal radiotherapy; IMRT, intensity-modulated radiotherapy; SCN, supraclavicular lymph node.

years $(\mathrm{p}=0.019)$, and non-squamous cell carcinoma histology $(\mathrm{p}=0.002)$ were associated with significantly poor PFS, while IMRT technique $(p=0.007), S C N$ metastasis from the lower lobe primary tumor $(\mathrm{p}=0.019)$, and CTV $\geq 300 \mathrm{~cm}^{3}(\mathrm{p}=0.001)$ were associated with significantly poor OS. Gender, clinical $\mathrm{T}$ stage, and SCN involvement itself were not of prognostic value to the clinical outcomes. No specific factor was known to have affected the in-field LRC. Based on multivariate analyses, IMRT technique $(p=0.010)$ and age $<60$ years $(p=0.032)$ were significant poor prognostic factors affecting the PFS. Interestingly, the RT technique was not a significant factor affecting the OS ( $p=0.197)$, while a CTV $\geq 300 \mathrm{~cm}^{3}$ was the only factor that had a significant effect on the OS $(\mathrm{p}=0.018)$.

\section{Discussion}

Few studies have reported the treatment outcomes following IMRT for NSCLC [12-14,16,18]. These previous studies not only included patients with stage IIIB disease, but also those with stage IIIA and even stages I/II. Although the current study included only N3-IIIB patients, the disease extent was still quite heterogeneous because of differences in the location of metastatic LNs and the CTVs. Despite definitive CCRT being the standard treatment option for patients with N3-IIIB NSCLC, 3D-CRT cannot safely deliver high radiation doses cases of large disease extent, especially in those involving SCN metastasis from lower lobe primary tumors, because of the normal tissue toxicity risk. Based on previously conducted studies, IMRT could result in significantly lower levels of grade $\geq 3$ TRP when compared with 3D-CRT, despite the large GTVs [12]. Furthermore, a subse- 
Table 5. Cox proportional hazards multivariate model for survival outcomes

\begin{tabular}{|c|c|c|c|c|}
\hline \multirow{2}{*}{ Variable } & \multicolumn{2}{|c|}{ Progression-free survival } & \multicolumn{2}{|c|}{ Overall survival } \\
\hline & HR (95\% CI) & p-value & HR (95\% CI) & p-value \\
\hline Treatment group & $2.498(1.246-5.008)$ & 0.010 & $2.160(0.670-6.965)$ & 0.197 \\
\hline Age & $0.514(0.280-0.943)$ & 0.032 & - & - \\
\hline Histology & $0.876(0.490-1.564)$ & 0.654 & $1.253(0.657-2.390)$ & 0.494 \\
\hline SCN from lower lobe & $0.872(0.379-2.003)$ & 0.747 & $1.554(0.490-4.927)$ & 0.454 \\
\hline $\operatorname{CTV}\left(\geq 300 \mathrm{~cm}^{3}\right)$ & $1.549(0.834-2.879)$ & 0.166 & $4.665(1.298-16.766)$ & 0.018 \\
\hline
\end{tabular}

$\mathrm{HR}$, hazard ratio; $\mathrm{CI}$, confidence interval; $\mathrm{SCN}$, supraclavicular lymph node; $\mathrm{CTV}$, clinical target volume.

quent study showed that IMRT with $4 \mathrm{D}-\mathrm{CT}$ was associated with reduced toxicity and improved OS [13]. Following the median follow-up of 16.5 months, the 2-year rates of diseasefree survival and OS were $38 \%$ and $46 \%$, respectively [14].

Patients receiving IMRT in the current study had significantly more frequent SCN metastasis from the lower lobe primary tumor and significantly larger CTVs than those receiving 3D-CRT. Even though group II patients had a larger disease extent and were therefore subjected to higher normal tissue doses, the incidences of grade 3 esophagitis and grade $\geq 2$ pneumonitis were not increased in this group based on the current study. Moreover, a comparable in-field LRC was achieved, while more frequent distant metastases occurred in patients receiving IMRT. While the 2-year rates of PFS and OS following definitive CCRT for patients with N3-IIIB NSCLC were $38.7 \%$ and $75.2 \%$, respectively, the corresponding rates of patients receiving IMRT were 19.3\% and $61.7 \%$, respectively (Table 4). However, direct comparison of the clinical outcomes between groups I and II should be made with caution because of the evident heterogeneity of the clinical characteristics. Although patients receiving IMRT had unfavorable survival outcomes, this might have occurred because these patients already had more adverse prognostic factors than those receiving 3D-CRT. The PFS at 2 years reported in this study seems inferior to that of previous studies (19.3\% vs. 38\%). This difference might have been due to the heterogeneous patient population with respect to stage, tumor location, and extent of nodal involvement. One retrospective study of IMRT reported a 2-year OS rate of 58\% in stage III patients [18], and the corresponding figure by the authors appears to be generally favorable when compared with the previous data. Taken together, IMRT could safely cover a larger disease extent than 3D-CRT, and yielded a favorable in-field LRC with no extra toxicity risk.

As shown in Table 3, the median time to progression following IMRT was only 6 months, and this was mostly due to early appearance of distant metastases. Interestingly, the OS was not as poor as the PFS in the current study. It is important to note that clinical outcomes following disease progression might be influenced by the availability of systemic treatment regimens, including targeting agents, which were not presented in detail in the current study. Although collection of biomarker data such as mutations in the epidermal growth factor receptor (EGFR) gene and/or anaplastic lymphoma kinase (ALK) gene was not the primary objective of the current study, $13(24.5 \%)$ and five $(9.4 \%)$ of 53 patients with adenocarcinoma exhibited EGFR gene mutations and $A L K$ rearrangements, respectively. Furthermore, 16 of these 18 patients exhibited disease progression, mostly distant metastases. In patients with N2-positive NSCLC, EGFR mutation was shown to experience more frequent distant relapse and have worse PFS following preoperative CCRT and surgery at SMC [19]. CCRT accompanied by treatment with cetuximab, a monoclonal antibody targeting EGFR, has demonstrated promising outcomes in patients with stage III NSCLC $[20,21]$. Moreover, favorable clinical outcomes have been reported in patients treated with the ALK tyrosine-kinase inhibitor, crizotinib [22]. Therefore, further improvement of clinical outcomes in the patients receiving definitive CCRT for N3-IIIB NSCLC could be expected if combining these targeting agents with RT.

As described above, the Surveillance, Epidemiology, and End Results (SEER) data demonstrated increased use of IMRT for patients with stage III NSCLC [15]. A radiation oncologists' practice environment can strongly influence utilization of the IMRT technique. Similarly, the reimbursement policies and practice settings were shown to have a great effect on utilization of IMRT for treatment of patients with breast cancer [23]. IMRT appears to have been utilized less frequently than necessary in Korea, mainly because the national health insurance system does not reimburse patients for this technique. The high cost of IMRT for lung cancer could be a considerable financial burden, resulting in financial toxicity $[24,25]$. Therefore, careful and reasonable decision making with consideration of the cost effectiveness should become a crucially important issue for the optimal 
utilization of up-to-date technologies and resources. Future research efforts should be directed toward solving these issues and development of biological markers.

\section{Conclusion}

The current study has several limitations, including a small number of patients, great heterogeneity in disease extent, and potential selection bias owing to the economic capacity of the patients. Nevertheless, the authors were able to demonstrate that IMRT was capable of delivering high radiation dose with no extra risk of lung toxicity in a definitive
CCRT setting for treatment of N3-IIIB NSCLC patients, especially those with extensive disease, such as lower lobe primary tumor with SCN metastasis. Since the early occurrence of distant metastasis was a major pattern of disease progression, careful patient selection and optimal combinations of systemic treatments, including targeting agents, are necessary to improve clinical outcomes.

\section{Conflicts of Interest}

Conflict of interest relevant to this article was not reported.

\section{References}

1. National Comprehensive Cancer Network. NCCN guidelines version 3, 2014. Non-small cell lung cancer [Internet]. Fort Washington, PA: National Comprehensive Cancer Network; 2014 [cited 2014 May 28]. Available from: http://www.nccn. org/professionals / physician_gls/pdf/nscl.pdf.

2. Auperin A, Le Pechoux C, Rolland E, Curran WJ, Furuse K, Fournel $\mathrm{P}$, et al. Meta-analysis of concomitant versus sequential radiochemotherapy in locally advanced non-small-cell lung cancer. J Clin Oncol. 2010;28:2181-90.

3. Curran WJ Jr, Paulus R, Langer CJ, Komaki R, Lee JS, Hauser $S$, et al. Sequential vs. concurrent chemoradiation for stage III non-small cell lung cancer: randomized phase III trial RTOG 9410. J Natl Cancer Inst. 2011;103:1452-60.

4. Ramnath N, Dilling TJ, Harris LJ, Kim AW, Michaud GC, Balekian AA, et al. Treatment of stage III non-small cell lung cancer: diagnosis and management of lung cancer, 3rd ed: American College of Chest Physicians evidence-based clinical practice guidelines. Chest. 2013;143(5 Suppl):e314S-40S.

5. Machtay M, Bae K, Movsas B, Paulus R, Gore EM, Komaki R, et al. Higher biologically effective dose of radiotherapy is associated with improved outcomes for locally advanced non-small cell lung carcinoma treated with chemoradiation: an analysis of the Radiation Therapy Oncology Group. Int J Radiat Oncol Biol Phys. 2012;82:425-34.

6. Schallenkamp JM, Miller RC, Brinkmann DH, Foote T, Garces YI. Incidence of radiation pneumonitis after thoracic irradiation: dose-volume correlates. Int J Radiat Oncol Biol Phys. 2007;67:410-6.

7. Oh D, Ahn YC, Park HC, Lim DH, Han Y. Prediction of radiation pneumonitis following high-dose thoracic radiation therapy by $3 \mathrm{~Gy} /$ fraction for non-small cell lung cancer: analysis of clinical and dosimetric factors. Jpn J Clin Oncol. 2009;39:151-7.

8. Edge SB, Byrd DR, Compton CC, Fritz AG, Greene FL, Trotti
A. AJCC cancer staging manual. 7th ed. New York: Springer; 2009.

9. Grills IS, Yan D, Martinez AA, Vicini FA, Wong JW, Kestin LL. Potential for reduced toxicity and dose escalation in the treatment of inoperable non-small-cell lung cancer: a comparison of intensity-modulated radiation therapy (IMRT), 3D conformal radiation, and elective nodal irradiation. Int J Radiat Oncol Biol Phys. 2003;57:875-90.

10. Liu HH, Wang X, Dong L, Wu Q, Liao Z, Stevens CW, et al. Feasibility of sparing lung and other thoracic structures with intensity-modulated radiotherapy for non-small-cell lung cancer. Int J Radiat Oncol Biol Phys. 2004;58:1268-79.

11. Murshed H, Liu HH, Liao Z, Barker JL, Wang X, Tucker SL, et al. Dose and volume reduction for normal lung using intensity-modulated radiotherapy for advanced-stage non-smallcell lung cancer. Int J Radiat Oncol Biol Phys. 2004;58:1258-67.

12. Yom SS, Liao Z, Liu HH, Tucker SL, Hu CS, Wei X, et al. Initial evaluation of treatment-related pneumonitis in advancedstage non-small-cell lung cancer patients treated with concurrent chemotherapy and intensity-modulated radiotherapy. Int J Radiat Oncol Biol Phys. 2007;68:94-102.

13. Liao ZX, Komaki RR, Thames HD Jr, Liu HH, Tucker SL, Mohan R, et al. Influence of technologic advances on outcomes in patients with unresectable, locally advanced non-small-cell lung cancer receiving concomitant chemoradiotherapy. Int J Radiat Oncol Biol Phys. 2010;76:775-81.

14. Jiang ZQ, Yang K, Komaki R, Wei X, Tucker SL, Zhuang Y, et al. Long-term clinical outcome of intensity-modulated radiotherapy for inoperable non-small cell lung cancer: the MD Anderson experience. Int J Radiat Oncol Biol Phys. 2012;83: 332-9.

15. Shirvani SM, Jiang J, Gomez DR, Chang JY, Buchholz TA, Smith BD. Intensity modulated radiotherapy for stage III non-small cell lung cancer in the United States: predictors of 
use and association with toxicities. Lung Cancer. 2013;82: 252-9.

16. Song CH, Pyo H, Moon SH, Kim TH, Kim DW, Cho KH. Treatment-related pneumonitis and acute esophagitis in non-smallcell lung cancer patients treated with chemotherapy and helical tomotherapy. Int J Radiat Oncol Biol Phys. 2010;78: 651-8.

17. Lee H, Ahn YC, Pyo H, Kim B, Oh D, Nam H, et al. Pretreatment clinical mediastinal nodal bulk and extent do not influence survival in N2-positive stage IIIA non-small cell lung cancer patients treated with trimodality therapy. Ann Surg Oncol. 2014;21:2083-90.

18. Sura S, Gupta V, Yorke E, Jackson A, Amols H, Rosenzweig KE. Intensity-modulated radiation therapy (IMRT) for inoperable non-small cell lung cancer: the Memorial Sloan-Kettering Cancer Center (MSKCC) experience. Radiother Oncol. 2008;87:17-23.

19. Ahn HK, Choi YL, Han JH, Ahn YC, Kim K, Kim J, et al. Epidermal growth factor receptor mutation and treatment outcome of mediastinoscopic N2 positive non-small cell lung cancer patients treated with neoadjuvant chemoradiotherapy followed by surgery. Lung Cancer. 2013;79:300-6.

20. Ready N, Janne PA, Bogart J, Dipetrillo T, Garst J, Graziano S, et al. Chemoradiotherapy and gefitinib in stage III non-small cell lung cancer with epidermal growth factor receptor and
KRAS mutation analysis: cancer and leukemia group $B$ (CALEB) 30106, a CALGB-stratified phase II trial. J Thorac Oncol. 2010;5:1382-90.

21. Blumenschein GR Jr, Paulus R, Curran WJ, Robert F, Fossella F, Werner-Wasik M, et al. Phase II study of cetuximab in combination with chemoradiation in patients with stage IIIA / B non-small-cell lung cancer: RTOG 0324. J Clin Oncol. 2011;29:2312-8.

22. Shaw AT, Yeap BY, Solomon BJ, Riely GJ, Gainor J, Engelman JA, et al. Effect of crizotinib on overall survival in patients with advanced non-small-cell lung cancer harbouring ALK gene rearrangement: a retrospective analysis. Lancet Oncol. 2011;12: 1004-12.

23. Smith BD, Pan IW, Shih YC, Smith GL, Harris JR, Punglia R, et al. Adoption of intensity-modulated radiation therapy for breast cancer in the United States. J Natl Cancer Inst. 2011;103: 798-809.

24. Chino F, Peppercorn J, Taylor DH Jr, Lu Y, Samsa G, Abernethy $\mathrm{AP}$, et al. Self-reported financial burden and satisfaction with care among patients with cancer. Oncologist. 2014;19: 414-20.

25. Zafar SY, Peppercorn JM, Schrag D, Taylor DH, Goetzinger AM, Zhong X, et al. The financial toxicity of cancer treatment: a pilot study assessing out-of-pocket expenses and the insured cancer patient's experience. Oncologist. 2013;18:381-90. 